\title{
Capítulo 11
}

\section{La prensa dominica integral en la Argentina. El caso de La Hoja Santiagueña}

María Mercedes Tenti"

\section{Introducción}

Conscientes del poder de la prensa, los redactores de La Hoja Santiagueña consideraban que este medio debía estar al servicio de las grandes ideas y causas, y en contra de la prédica "subversiva y malsana" que oprimía a los pueblos. En un primer momento fue el único periódico católico de Santiago del Estero y se erigió en baluarte de la defensa de los valores cristianos, a su juicio, puestos en peligro por el modernismo que apuntaba, especialmente, a desestabilizar la familia, las buenas costumbres, la moral pública y la dignidad social.

Su prédica se dirigía en contra de todo lo que creía atentaba contra esas virtudes cristianas: el cine, las modas, el teatro, la vagancia infantil, el laicismo, el comunismo y el socialismo. Para oponerse se levantaba, en primer lugar, la Iglesia como institución núcleo de la fe y las buenas obras y, luego, la familia cristiana, la escuela católica, las

* Integrante de la Red de Investigadores en Historia de la Iglesia y la Religiosidad en el NOA, de la Red de Estudios sobre el Peronismo y de la Red Intercátedras de Historia de América Latina Contemporánea. 
instituciones armadas —encargadas de cuidar el orden- y la prensa católica como expresión directa de resistencia al caos provocado por la vida moderna.

Desde la perspectiva de reconstrucción eclesial, instaurada en la provincia ${ }^{1}$ a partir de la instalación del obispado en 1910, la Iglesia se propuso salir a la calle y adquirir mayor visibilidad ante los embates del mundo moderno. La Orden dominicana no fue ajena a esta iniciativa y, a través del periódico La Hoja Santiagueña, instaló entre sus lectores problemas que compartía con los postulados del catolicismo de entonces y que, consideraba, atentaban contra la formación y costumbres del pueblo santiagueño.

A comienzos del siglo XX, para algunos autores, el clima católico imperante (Di Stefano y Zanatta, 2000; Zanatta, 2002) era de decaimiento, como consecuencia de factores originados en la Argentina decimonónica, entre ellos, el conflicto entre la Iglesia y el Estado liberal, los procesos de laicización, las aspiraciones del liberalismo de relegar al catolicismo al ámbito privado y la falta de consolidación de las asociaciones católicas. A pesar de esta visión, el catolicismo enfrentaba el desafío de la modernidad manteniendo frente a las contingencias, un núcleo dinámico alrededor de las parroquias, cuyas sedes eran el centro de las actividades religiosas, sociales y políticas. ${ }^{2}$

Entrado el nuevo siglo, la Iglesia comenzó a plantearse la necesidad de cierto ordenamiento y centralización de las decisiones. En esta perspectiva, se buscó una mayor eficacia del gobierno eclesiástico y su organización interna fue prioritaria. Se crearon nuevas diócesis, ${ }^{3}$ se dio primacía al clero secular mediante una mejor formación, disciplina y

1 Santiago del Estero es una provincia periférica situada en el noroeste argentino, alejada de los centros de decisión.

2 Los atrios de las iglesias eran, desde la sanción de la Constitución en 1853 el lugar en donde se confeccionaban los padrones electorales y se realizaban los comicios.

3 Santiago del Estero fue una de ellas, creada en 1907, aunque su primer obispo asumió recién en 1910. 
mayor protagonismo; también se profundizó la educación religiosa ${ }^{4}$, se propició el nacimiento de nuevas asociaciones laicas, se conformaron agrupaciones políticas católicas, se alentó la prensa católica para oponerse a la liberal, socialista y comunista, se organizó la Acción Católica Argentina y la cuestión social del mundo laboral comenzó a ser tema de la agenda eclesiástica.

\section{El catolicismo integral}

Se conoce con el nombre de catolicismo integral al modelo impulsado desde Roma con el propósito de construir una sociedad cristiana bajo la enseñanza y la conducción de la Iglesia católica. Se planteaba hacer frente, en primer lugar, al liberalismo que ocasionaba, a su juicio, todos los males de la sociedad; otro enemigo lo constituía el socialismo. Este esquema de confrontación identitaria se originó a partir de El Syllabus, introducción de la encíclica Cuanta Cura (1864), que mostraba una postura intransigente frente a los valores de la modernidad. Se proponía "[...] edificar una sociedad cristiana según la enseñanza y bajo la conducta de la Iglesia" (Esquivel, 2000, p. 3), por lo que ésta no se conformaba con quedar recluida en el ámbito privado, como quería confinarla el liberalismo. Por el contrario, pretendía que el poder temporal estuviera bajo el abrigo del poder espiritual, representado por ella. La prédica contra estos modelos societales amenazadores traía aparejada la consolidación de la presencia institucional y social de la Iglesia. A partir de entonces, el catolicismo aspiraba a instaurar un sistema normativo católico como principio organizador de la sociedad.

Dentro de este proceso de reorganización, denominado romanización, comenzó la conformación de una nueva matriz católica, como opción contra los avances del socialismo y del liberalismo. Este proyecto integral buscaba expandir la influencia del catolicismo a todo el tejido social, proyecto en el que la Iglesia sería la responsable directa. Se tenía la convicción de

4 En particular luego de la sanción de la ley 1420 en 1884, que establecía la enseñanza gratuita, obligatoria y laica. 
que la fe cristiana era el principio de verdad absoluta, en consecuencia, la Iglesia católica era la norma suprema y la única garante de la unidad, de allí la importancia de su presencia social (Mallimaci, 1998, p.5).

Se planteaba un conflicto triangular, tres modelos societales que se enfrentaban: el liberal, el socialista-comunista y el católico (Mallimaci, 1998, p. 17). El liberalismo se había instalado en la Argentina desde mediados del siglo XIX, con la Constitución de 1853 y, especialmente, con las leyes laicas de educación común, de registro civil y matrimonio civil; se centraba en el humano y prescindía de la presencia de Dios. El comunismo ateo, atacaba la esencia de la sociedad desde distintos frentes: el soviet judío, el México revolucionario y la España republicana. Su objetivo era poner fin a la influencia de la Iglesia en el mundo, a la patria y sus Fuerzas Armadas y a la propiedad privada. El modelo católico buscaba unir las ideas rectoras de Iglesia, patria, fuerzas armadas y hogar, como fundamentos de la nacionalidad. Sus raíces nacionalistas se nutrían de la España colonizadora, afianzadas en las luchas por la Independencia y la acción civilizadora del Ejército Nacional, de la mano de la Iglesia. Se consolidaba lo que Zanatta denomina "el mito de la nación católica" (2002).

Para combatir a los enemigos del catolicismo y posicionarse mejor frente al proceso de laicización de la sociedad, ${ }^{5}$ la jerarquía eclesiástica impulsaba la conformación de asociaciones católicas, como los Círculos Católicos de Obreros y la Acción Católica Argentina, entre los más significativos, la educación religiosa en escuelas públicas y privadas, la prensa católica, para contrarrestar los efectos de la prensa liberal o comunista, y las movilizaciones católicas en espacios públicos, para dar visibilidad al naciente catolicismo de masas.

5 Pérez y Santiago (2008) consideran a la laicización como el proceso de delimitación de esferas (religiosa y política) en las sociedades occidentales (pp. 10-11). 


\section{La prensa católica en Argentina}

La prensa católica adquirió visibilidad a partir de la discusión de las leyes laicistas decimonónicas, a través de periódicos de filiación católica que defendían la educación religiosa en las escuelas y la presencia de la Iglesia en el quehacer del Estado, presencia con la que no acordaban los políticos liberales y otras publicaciones —semanarios, revistas, entre otros- que dependían de parroquias u asociaciones católicas. Tal como lo analiza Auza en su libro Católicos y liberales en la generación del 80 (1992), si bien ambos sectores coincidían en la mayoría de sus posturas, los puntos de dispersión se centraban en aquellas en que se ponía en discusión la cuestión religiosa. En el siglo XX, el accionar de la prensa católica fue mucho más activo. La lucha contra el modernismo, el liberalismo y el comunismo necesitaban de un arma efectiva que penetrara al interior de todos los hogares, por ello había que impulsar la expansión y consolidación de la prensa católica. Numerosas investigaciones dan cuenta de su accionar en Argentina; se pueden mencionar los trabajos de Auza (2000a, 2000b) para el ámbito bonaerense y de Lida (2006), quien relaciona el papel de la prensa con la construcción de la identidad política católica; en Córdoba, Rointeburd (2002) analizan su rol en los grandes enfrentamientos por las reformas liberales y en Santiago del Estero, Guzmán (2011) estudian expresiones del modernismo católico, y Tenti (2008b) el periódico El momento. Para el caso de La Hoja Santiagueña, Gramajo de Martínez Moreno (2005) indaga sobre esta publicación dominicana, reseña sus propósitos, temas principales y la obra de la Orden en la provincia, reflejada en la publicación.

\section{La Hoja Santiagueña}

La Orden dominicana, en la primera mitad del siglo XX, tuvo en la Argentina una activa intervención a través de periódicos y revistas católicas publicadas en diferentes ciudades como Buenos Aires, Mendoza, Córdoba, Tucumán, San Luis, San Juan y Santiago del Estero. En Santiago del Estero y Tucumán se publicó La Buena Noticia y las denominadas Hoja, vieron la luz en diferentes partes del país (González, 
2001). Cuando en 1924 apareció La Hoja Santiagueña, no había otra publicación católica en Santiago del Estero. Como antecedentes, se puede citar el diario El País, el cual, si bien no era un órgano de la Iglesia, defendió la postura de la misma en ocasión de la reforma de la Constitución Provincial en 1894 (Tenti, 2013); El Fiel Católico, que surgió en 1885, voz oficial de la Iglesia; Primaveral, revista quincenal que se publicó en 1818, órgano del Centro Católico de Estudiantes.

En su primer número, La Hoja se presentaba como "un modesto órgano de la prensa [...] Un periódico eminentemente local, aunque débil, pero armonioso del sentimiento de la sociedad santiagueña" ( $\mathrm{La}$ Hoja Santiagueña, 19 de abril de 1924). La publicación tuvo el visto bueno del obispo Yáñiz y Paz y de la Orden dominicana. El periódico fue creado por iniciativa de las socias de la Asociación del Rosario Perpetuo — fundada en 1898 - para celebrar sus bodas de plata. Su primer director fue fray Juan de Santa María Romero; fueron ocupando la dirección los sucesivos priores, destacándose entre ellos fray Reginaldo Saldaña Retamar (1933-1937) de importante actuación como historiador, periodista, orador y misionero (González, 2001).

Su lema era "orden de la verdad", "pese a quien pese y duela a quien duela" y su razón, "defender al catolicismo y la patria, fundamentos del orden" (La Hoja Santiagueña, abril de 1937). Su propósito era convertirse en "el eco de la sociedad de Santiago, de propaganda dominicana y de servir a la cultura moral y social, a fin de estabilizar el hogar conmovido en sus fundamentos por ideas disolventes" (La Hoja Santiagueña, octubre de 1923). La Hoja se posicionaba en contra del periodismo mercantilista y utilitario. Su campaña era de regeneración moral frente al desenfreno de las pasiones y a la falta de asimilación de la doctrina cristiana (La Hoja Santiagueña, noviembre de 1937). Sostenía que no era "órgano exclusivo de la Comunidad y asociaciones dominicas", sino que era una "publicación católica al servicio de los intereses católicos de la ciudad y la provincia" (La Hoja Santiagueña, julio de 1935).

La mayoría de los artículos aparecen sin firma y era el director quien daba su impronta. Entre los firmados, se advierte la pluma de algunos dominicos de reconocida trayectoria, como el mismo Saldaña Retamar, quien solía firmar con seudónimos quichuas (dialecto 
santiagueño del quechua peruano) como Rumi Ampatu (Sapo de piedra), Allpa Sichi (Tierra dura), Cusi Kollur (Lucero alegre), entre otros; o los padres Battista, Surita y Palomba (Gramajo de Martínez Moreno, 2005, p. 205). Escribían también los obispos santiagueños o algún representante - aunque especialmente, en comunicados o decretos-. Solía transcribir textos publicados en periódicos y revistas de variada procedencia, según los intereses del momento. Así, aparecían intelectuales católicos como Orestes Di Lullo —-médico santiagueño de reconocida trayectoria - con escritos referidos a costumbres regionales, monseñor Gustavo Franceschi, director de la revista Criterio, en amparo del movimiento nacionalista español, o nombres internacionales que variaban desde el papa Pío XI en la encíclica "Dinivini Illius Magistri”, en la que se pronunciaba contra el naturalismo, o Mussolini en su defensa de la religión.

La Hoja Santiagueña se plantaba como un instrumento de la cruzada del integrismo, para salir a la arena pública y contribuir a regenerar la sociedad corrompida por el modernismo, enfrentar las ideas socialistas y comunistas e impulsar una cultura católica que se nutriese del pasado y de la tradición. El nuevo orden cristiano debía enfrentar también al sistema liberal-burgués que corrompía las costumbres, para ello había que re cristianizar la sociedad; la prensa era uno de los vehículos para conseguirlo.

La publicación salió a la calle con distinta frecuencia y diferente tamaño, a lo largo de sus 31 años de vida. ${ }^{6}$ Su instalación en la sociedad católica no fue tarea fácil, ya que se distribuía directamente en el templo y por suscripción. Con todo, llegaron a editarse 800 ejemplares en tiradas normales y 1300 en ocasión de su décimo aniversario, ambos números eran elevados para una provincia con poca población como Santiago del Estero. ${ }^{7}$ Su campaña de moralización de las costumbres generó también críticas a la dirección del periódico, según se

6 Quincenal, mensual y trimestral, salió a la luz hasta 1955. Su tamaño osciló entre cuatro y ocho páginas.

7 Según el censo de 1947 tenía 479.473 habitantes de los cuales, solo el 17\% habitaba en la capital provincial y con altos índices de analfabetismo (INDEC, 1947). 
advierte en algunos artículos referidos a temas relacionados con las modas propias de la modernidad, que criticaba (La Hoja Santiague$\tilde{n} a$, julio de 1936). Para el presente trabajo se analizan los temas que dan sustento a su postura ideológica dentro del integrismo católico: la prensa, las costumbres, la educación, la concepción de Dios, patria y hogar, las tradiciones y las festividades religiosas.

\section{La prensa}

Frente al avance de la prensa liberal o comunista, que se concretaba por todos los frentes — diarios, radios, revistas, libros, folletos- la prensa católica debía tomar la delantera y darles batalla. La tarea era desigual pero no por ello menos valedera. La Hoja consideraba a la prensa como un huésped que se instalaba en cada casa influyendo en el pensamiento de sus moradores; "El sectarismo y el indiferentismo" en materia religiosa se había apoderado de la prensa mundial, que le hacía la guerra a la Iglesia de Cristo. Frente a ello, el deber de los católicos era crear su propia prensa (La Hoja Santiagueña, 12 de agosto, 11 de octubre de 1924).

La amenaza del protestantismo, del socialismo, del comunismo y de las grandes empresas judías — a juicio de La Hoja - se canalizaba a través de periódicos y libros "malsanos", de allí la importancia de la publicación santiagueña, único medio católico en la provincia a lo largo de prácticamente todos sus treinta años de existencia (Salvo, 1939), concebida según el moderno concepto de propaganda, en defensa de la cultura católica.

Había que desterrar de los hogares los diarios liberales que atentaban contra la familia, la moral cristiana y la patria (La Hoja Santiagueña, enero de 1929) ya que la prensa atea o descreída atraía a los católicos con estímulos sensoriales y propaganda. Llamaba a la colaboración de organizaciones y asociaciones para hacer oposición a la prensa liberal, enemiga declarada de la fe religiosa, "En Santiago solo se leen diarios y revistas del enemigo" (La Hoja Santiagueña, enero de 1930), sostenía. Había que poner al hogar, a la mujer y a los niños a cubierto de la ola de disolución. La dicotomía amigo-enemigo era 
una constante. El apostolado moderno consistía en difundir los diarios católicos, colaborar con suscripciones y anuncios y romper la indiferencia para el sostenimiento de la publicación.

\section{Las costumbres}

Otro objetivo del periódico era luchar contra el decaimiento de las costumbres, propio de la vida moderna. Atacar los males de la sociedad se convirtió en una verdadera cruzada. Para La Hoja, el cine era una de las causas principales del abatimiento moral y dislocamiento de los hogares (La Hoja Santiagueña, 17 de mayo de 1924). A poco tiempo de su creación, propuso a la intendencia conformar una comisión censora (La Hoja Santiagueña, 11 de septiembre 1924), propuesta que no fue tenida en cuenta. Proposición similar sugirió — también sin éxito- para las obras teatrales. Opinaba el periódico que las autoridades comunales privilegiaban más la salud física — por la proliferación de enfermedades infectocontagiosas- y descuidaban la moral (La Hoja Santiagueña, 14 de abril de 1925).

Enfocaba el ataque a través de un discurso higienista: el cine perjudicaba la salud, era antihigiénico por tratarse de un espacio reducido, poco ventilado y al que no entraba la luz del sol. No solo perjudicaba la vista, fatigaba los ojos, sino que hacía estragos en el sistema nervioso; "una turba de neurasténicos son los hijos del amor al cine" ( $\mathrm{La}$ Hoja Santiagueña, 1 de noviembre de 1926), afirmaba.

Constituía uno de los principales peligros de la vida moderna, ya que desorganizaba la sociedad, borraba la religión, desmoralizaba al pueblo. Criticaba el argumento de la mayoría de las películas, basado en adulterio o amores prohibidos, igual que el teatro con cuadros “espeluznantes, trágicos y deshonestos”, en el que abundaba el género libre "para satisfacción de todas las corrupciones" (La Hoja Santiagueña, 1 de diciembre de 1926, enero de 1929).

La vestimenta era también motivo de crítica, en particular la femenina. Frente al hedonismo dominante, por el que las mujeres exageraban en mostrar las formas, la Iglesia tuvo que intervenir colocando carteles en los templos, advirtiendo que no se daría la comunión a 
quienes no concurrieran vestidas modestamente. La consecuencia de esta moda era la deshumanización femenina, al dejar de lado su formación espiritual. Advertía que estas costumbres "aberrantes" se daba aun en jóvenes que concurrían a colegios católicos (La Hoja Santiagueña, 1 de julio de 1926).

La desnudez de la mujer en el vestir amenazaba la familia y la sociedad. También constituían una amenaza los concursos de belleza. Periódicamente publicaba las instrucciones de la Congregación del Concilio sobre fomentar la modestia en el vestido. Aquella que se vistiera deshonestamente no debía ser admitida a la comunión, ni podía ser madrina de bautismo o confirmación. En casos extremos, hasta podía ser expulsada de la iglesia.

El baile moderno también constituía un peligro para la sociedad. Buscaba ratificar su postura adhiriendo a otras, aun a las que combatía. Tal su adhesión a la disposición del Consejo de Cultura Física de Moscú que prohibía el foxtrot, tango y charlestón, por constituir una amenaza para la juventud (La Hoja Santiagueña, 8 de marzo de 1927).

La vagancia infantil era motivo de su atención, por atentatoria del orden social. La Hoja consideraba al vago como sospechoso y peligroso. Consideraba a la vagancia y a la delincuencia infantil como causa directa de criminalidad (La Hoja Santiagueña, 1 de diciembre de 1926). La ociosidad de niños y jóvenes conducía al desenfreno en el lenguaje, conversaciones indecorosas y a expresiones obscenas pintadas o escritas en las fachadas de las casas (La Hoja Santiagueña, enero y febrero de 1929). Las pintadas en las paredes, con leyendas con referencia a "lo grosero, pornográfico y sucio" ponían en peligro la niñez que así sería "la canalla de nuestra sociedad" (La Hoja Santiagueña, octubre 1 de 1934).

Los deportes modernos como la equitación y el ciclismo eran objeto de críticas, en especial los practicados por mujeres que montaban a caballo o en bicicleta, con "falta de pudor, recato y decencia". Instaba a las mujeres a vestirse con pollera larga y se posicionaba en contra del uso de pantalones (La Hoja Santiagueña, marzo de 1938). En realidad, estas prácticas constituían nuevas formas de entretenimiento para las jóvenes, que cabalgaban por el parque y daban vueltas en bicicleta alrededor de la plaza. La juventud iba ganando los espacios 
públicos, ante la mirada preocupada de la Iglesia. Similar reprobación fue pasible para la natación y el esparcimiento en clubes con piscinas, que compartían hombres y mujeres en trajes de baño. Afirmaba que los balnearios constituían espectáculos ofensivos a la moral, donde señoras y jovencitas perdían el pudor.

Ante el avance de estas modas perniciosas, el episcopado emitió un comunicado — que publicó La Hoja - en el que manifestaba su disconformidad con la conducta cristiana en estos lugares públicos. El aviso expresaba su preocupación por la "promiscuidad simultánea de sexos en las piletas de natación”, en diversiones de verano con vestimenta inadecuada y el uso de trajes improcedentes en algunos deportes públicos femeninos, concursos gimnásticos, concursos de belleza y desfiles de modas (La Hoja Santiagueña, septiembre de 1940).

Como correctivo recomendaba la modestia en el vestido para la concurrencia a misa y a los sacramentos. Las recomendaciones eran bastante severas: para las mujeres, el vestido debía llegar al cuello en la parte superior, la falda por debajo de las rodillas y las mangas debajo del codo. No se debía permitir la entrada de mujeres sin medias al templo. El periódico se hacía eco de la pastoral del episcopado que prohibía para los católicos fiestas mundanas como bailes, corsos y tés danzantes, que contradecían el culto católico. Adhería a las prohibiciones prescritas para los creyentes, por el obispo Audino Rodríguez y Olmos, ${ }^{8}$ exponente del integrismo en la provincia:

1. Bailes entre los dos sexos y bailes de niños.

2. Espectáculos teatrales mundanos.

3. Toda reunión donde se mezclasen juegos de azar, caballitos y ruleta.

Para los mismos fines eran permitidos:

1. Conciertos vocales o instrumentales.

2. Rifas o tómbolas.

8 Rodríguez y Olmos se desempeñó como obispo de Santiago del Estero entre 1927 y 1940. 
3. Bazares.

4. Conferencias y actos literarios.

5. Juegos de deportes dignos de hombres y mujeres mundanos.

6. Corsos de flores.

7. Picnics y excursiones.

8. Cinematógrafos, previo examen y selección de cintas.

9. Óperas y dramas, previo examen (La Hoja Santiagueña, abril de 1930).

Si bien se pretendía controlar las costumbres del pueblo católico, ello resultaba muy difícil de llevar a cabo por cuanto la modernidad avanzaba en la provincia y era blanco de crítica de los dominicos, que veían con preocupación cómo las mujeres dejaban el hogar para concurrir, junto con los hombres, a confiterías y bares, usaban melena como ellos, tomaban bebidas espirituosas y fumaban. Ya no respondían al modelo de "reina del hogar".

Siguiendo una tendencia en boga en la Iglesia argentina, La Hoja evaluaba la asistencia a las celebraciones religiosas los domingos y días festivos. Hacia 1933, la ciudad contaba con 40.000 habitantes, extendida con barreadas nutridas hacia tres sectores: Vinalar al sur, Las Carreras al oeste y Cachi Pampa al norte. Siguiendo el ejemplo del cura párroco de la catedral, Mons. Retambay que había contado 995 personas en las cinco misas de los domingos, se contabilizaron la asistencia a misa en San Francisco, Santo Domingo y La Merced ${ }^{9}$ —en total cuatro misas-, ninguna a pleno y sin llegar a mil asistentes. En los otros lugares en donde se realizaba la celebración eucarística: Belén, Belgrano, Hospital, Franciscanas, Asilo de Dominicas, San Roque y Seminario era exiguo el número de concurrentes. A pesar de trabajarse con empeño, de organizarse catecismos, novenas, misiones, concentraciones, los resultados no eran los deseados para el análisis de Saldaña Retamar (La Hoja Santiagueña, octubre de 1933), destacado orador, periodista, prior de Santo Domingo —en Santiago del Estero- en dos oportunidades y entusiasta organizador de misiones por el interior santiagueño.

9 Las otras tres iglesias más importantes, ubicadas en el centro de la ciudad. 


\section{La educación católica}

Desde el primer número, La Hoja comenzó a dar cuenta de su vocación pedagógica, consignaba las dos escuelas creadas por la Orden en la provincia: fray Justo Santa María de Oro, de mujeres, y fray Juan Grande, de varones, que funcionaban a la tarde y a la mañana, respectivamente. Para las niñas se había instalado un taller para enseñar hilados y tejidos de seda, algodón y lana (La Hoja Santiagueña, abril de 1924).

Veía, con preocupación, la política de suspensión de subsidios que se otorgaban a los colegios católicos. Argumentaba que las escuelas confesionales, en realidad, costaban al erario público la cuarta parte de lo que suponía su mantenimiento y les proporcionaban a los alumnos ropa y calzado y daban enseñanza integral, cultivando el alma y el corazón (La Hoja Santiagueña, 6 de marzo de 1927). La educación de entonces era, a juicio de los editores, poco cristiana y atentaba contra la integridad moral de los niños. Los padres tenían la obligación de darles educación verdadera, inculcarles la búsqueda de la verdad, el amor al bien y el respeto por la existencia de Dios (La Hoja Santiagueña, octubre de 1927).

La Hoja registraba las escuelas católicas existentes en la provincia: en total, 16 escuelas con locales propios, 1.514 alumnos y 36 maestras. Se debe tener en cuenta que, en el censo de 1914, Santiago del Estero contaba con 397 escuelas para toda la provincia, 33.140 alumnos y 738 maestros (INDEC, 1917, p. 82). Hasta fines de la década de los años treinta y con el aporte de las escuelas Láinez, ${ }^{10}$ el número de establecimientos primarios aumentó. Según el censo de 1947, la tasa de analfabetismo era del 31,1 \%, cuando la media del país era del 13,6\% (INDEC, 1947, t, I, p. 83; t, II, p. 419); de manera que la educación se encontraba en déficit. Las escuelas católicas, dependientes de las órdenes religiosas eran minoritarias y con escaso número de alumnos, pese a que, en el mismo censo, se registra que el 97,1\% de la población de la provincia era de religión católica.

10 Las escuelas Láinez eran escuelas creadas y sostenidas por el Estado nacional. 
Tabla 1. Escuelas católicas existentes en la provincia en 1929

\section{Escuelas dominicanas}

Esc. Fray Juan Grande de Varones, funciona desde 1813, alumnos 93, tres maestros, local propio, dirigida por el prior, fray Battista.

Fray Justo Sta. María de Oro de mujeres, 110 alumnas, tres maestras, $\mathrm{V}^{\circ}$ Orden, dirigida por el prior.

Esc. Franciscanas:

Colegio San Francisco de artes y oficios, gran local propio atendido por religiosos, 298 alumnos, 6 maestros.

Esc. San Antonio, en La Banda, local propio, 170 alumnas, 5 maestras.

Esc. Santa Inés. Local propio. 170 alumnas, 5 maestras.

Esc. San Francisco Solano, local propio, infantil, 36 alumnas una maestra.

Esc. Taller del Apostolado de la oración, 145 alumnas mujeres, 5 maestras, local propio.

Esc. Dominical, 80 alumnas mujeres, dos maestras.

Esc. Taller de La Banda de la V ${ }^{\circ}$ Orden Tercera, 2 maestras, 102 alumnas local propio.

Esc. Sta. Rosa de Viterbo, en Clodomira, mixta, de la $3^{\circ}$ Orden, 90 alumnos, 2 maestras.

Esc. San Francisco, de Fernández, 120 alumnos mixta 2 maestras, local propio de la Tercera Orden.

Esc. San Roque, de Taboada, 140 alumnos, tres maestras, local propio de la Tercera Orden.

Total, de esc. Franciscanas: 12, atendidas 6 por el P. Benito Corsi, 5 por el P. Luis Recabarren y 1 por el P. Antonio Chacón.

Escuelas mercedarias

San Pedro Nolasco, de varones, 70 alumnos, dos maestros, local propio.

Esc. Sta. Filomena, 2 maestras 60 alumnas.

Fuente: elaboración propia a partir de La Hoja Santiagueña, marzo de 1929.

Además de enviar a los niños a escuelas confesionales, el periódico instaba a los padres, madres y personas con niños a cargo, a mandarlos a la iglesia Santo Domingo para recibir educación cristiana. También miraba con preocupación cómo los egresados de las universidades nacionales lo hacían como intelectuales descreídos, ajenos de la vida espiritual. La universidad laica, afirmaba, enfermaba el cuerpo social (La Hoja Santiagueña, abril y mayo de 1929).

En ocasión del cincuentenario de la sanción de la Ley 1420, que establecía la educación gratuita, obligatoria y laica, el periódico inició 
una campaña tendiente a esclarecer los alcances de dicha ley, coincidente con el restablecimiento en algunas provincias de la enseñanza religiosa en escuelas estatales. El periódico aclaraba que la ley instauraba la educación obligatoria, gratuita y gradual — no laica-, permitiendo a los ministros autorizados del culto enseñar religión fuera del horario escolar. Seleccionaba textos oficiales que, a su juicio, se oponían al laicismo (La Hoja Santiagueña, junio 15 y julio 1 de 1934). Con ello buscaba argumentar a favor de la inclusión de la enseñanza religiosa.

Luego de sancionada la Constitución Provincial de 1939, que ratificaba la enseñanza laica, ${ }^{11}$ La Hoja continuó con su prédica en pro de la enseñanza religiosa en las escuelas. Dejando de lado si el Estado debía hacerse o no cargo de la educación, buscaba fundamentos filosóficos y políticos para destacar la importancia de la religión, citando los más disímiles pensadores como Plutarco, Rousseau y Voltaire, en afirmaciones descontextualizadas que sustentaban sus teorías.

Señalaba cuatro errores arraigados acerca de la educación. El primero, el naturalismo, que sostenía que el ser humano nacía bueno, sin reconocer el pecado original. El segundo, la educación sexual que era, más que un correctivo, un incentivo. El tercero, la preeminencia de la educación física, que usurpaba el tiempo que debía dedicarse a la vida religiosa y a la familia; y el cuarto, la escuela mixta, que iba en contra de la ciencia de la educación y de la pedagogía. La proximidad de niños de ambos sexos daba por resultado la precocidad sexual y fomentaba la perversión (La Hoja Santiagueña, septiembre de 1940).

\section{Dios, patria y hogar}

La Hoja consideraba que la igualdad no existía en la sociedad ni en la república. La igualdad solo existía ante Dios y en el cristianismo. "La igualdad, en cuanto es posible, no existe sino en el cristianismo, es decir, la única doctrina moral que ha logrado suprimir en el mundo

11 A pesar de la participación del obispo Rodríguez y Olmos como convencional constituyente. Al respecto ver Tenti (2004). 
la esclavitud", afirmaba (La Hoja Santiagueña, noviembre de 1929), de allí la necesidad de brindar conocimientos para arraigar la fe de los que ya la tenían y abrir los ojos de los que la desconocían. La influencia benéfica de la religión en los pueblos, se traslucía en la opinión del líder fascista Mussolini, transcripta por La Hoja:

Estoy firmemente convencido que la religión es necesaria para el pueblo. Tendría valor, aunque fuera solamente por su gran influencia moral. Pero es aún más preciosa para los pueblos porque los eleva a un ideal espiritual más alto. Es una fuerza que consolida y modera, que mantiene a los pueblos en los principios de la justicia y de la virtud (...) Allí donde hay disciplina religiosa hay disciplina civil... (La Hoja Santiagueña, agosto de 1930).

Para atacar los males del modernismo, la piedra angular de la sociedad la constituía la acción y autoridad de los padres. Su deber era cuidar a sus hijos para que no cayeran en peligro e inculcarles las virtudes cristianas. Sin embargo, muchos abandonaban su deber más sagrado que era proteger a la familia (La Hoja Santiagueña, 8 de julio de 1925).

Las fechas patrias constituían ocasión para que el periódico exaltara la obra de los próceres, en pro de la conservación del sentimiento nacional y de la exaltación de las virtudes morales y cívicas, afirmaba La Hoja imbuida de los principios del nacionalismo católico:

Necesitamos conservar incólume, el sentimiento nacional, característico de la sociedad argentina, en sus virtudes morales y cívicas, en sus costumbres sanas y bien inspiradas, en su idealismo puro, en su respeto a sus tradiciones, a su credo religioso, generador admirable de todos los altruismos y heroicidades de la epopeya. Mantengamos en nuestro corazón el amor, al suelo natal, al cielo que nos ampara, al emblema de la Patria, a los nombres de los obreros generosos que realizaron la tarea inmortal, a las instituciones armadas encargadas de cuidar el orden, de las fronteras y la de defender la nación ante los peligros de enemigos lejanos o próximos que nos acechan... (La Hoja Santiagueña, 1 de marzo de 1927). 
El amor al suelo natal, a la bandera y a las instituciones armadas encargadas de cuidar el orden y defender la soberanía - daba cohesión y evitaban la penetración de ideas foráneas. Para infundir el nacionalismo, la enseñanza cívica era imprescindible. Al niño debía inculcársele que después de Dios no había nada más importante que la patria:

Hay que decirlo con ruda franqueza, porque cuando se llega a extremos que hoy tocamos, no caben los eufemismos. El mundo pasa por una revolución tan completa como universal, con el socialismo y el comunismo que van enseñoreándose de los pueblos para pervertirlos en forma furtiva y sigilosa, pero firme y segura, mientras los elementos católicos se resignan a todos los vasallajes impuestos por aquellos (La Hoja Santiagueña, enero de 1929).

Veía con preocupación que disminuía el fervor patriótico en las nuevas generaciones. Como signo de su localismo La Hoja consideraba que también había que enseñar a los niños historia santiagueña, para que conociesen sobre la patria chica. Una de las formas de hacerlo era poniendo el nombre de un santiagueño ilustre en las escuelas y aulas (La Hoja Santiagueña, abril de 1927.

El hogar cristiano debía fortalecerse para evitar el avance del comunismo y del modernismo que corrompían la vida social y amenazaban la patria:

El bolcheviquismo, ha tomado a nuestra Nación, como centro de sus terribles actividades subversivas, y es de suponer que los poderes públicos estén alerta, para adoptar en el momento oportuno, las medidas del caso, para reprimirlas con las energías que lo hiciera antes (La Hoja Santiagueña, noviembre de 1927).

El rol de las madres en la formación cristiana de niños y jóvenes era fundamental. Los padres ocupados en sus negocios o trabajos no podían brindarles la atención que se merecía, de allí el papel de la mujer en el hogar, frente a los embates del mundo moderno. La idea de nación y de patria se alimentaba con nociones de orden social. Los inmigrantes que no se connaturalizaban con la nación solo tenían con 
ella un vínculo material, no respetaban la nacionalidad y la patria en que vivían y proliferaba el comunismo anárquico ${ }^{12}$ (La Hoja Santiagueña, mayo de 1930). La inmigración sin control atentaba contra la estabilidad de la nación:

Inmigrantes, cordialmente acogidos, se largan a propagar el ideario disolvente (...) No respetan a la nación en que viven y progresan porque no se connaturalizan con ella. No saben o se olvidan que la idea de la nación es idea de porvenir. La nación perdura, mientras que los hombres pasan. Nación sin orden legal no es nación (La Hoja Santiagueña, noviembre de 1927).

Las ideas hostiles — propias del nacionalismo en boga- atravesaban la publicación, al acusar a los extranjeros y judíos de responsables por la introducción de ideologías comunista, socialista o anarquista. En abril de 1938 La Hoja dedicó una página al acto realizado en la sala del cine Renzi por la Falange española, consistente en distribución de víveres y caramelos a niños pobres de Santiago del Estero y a sus familias. El secretario comarcal de la Falange leyó una proclama en contra de los que persiguieron a la Iglesia española, mataron sacerdotes, religiosos y religiosas, destruyeron templos y altares y "abrieron las puertas al engendro judío del comunismo". Reseñaba cómo, el capellán de la Falange, Ramiro Melero Portas, explicó a los presentes por qué la falange se levantaba para expulsar a "los rusos rojos".

Para La Hoja, los componentes de la sociedad eran heterogéneos. Unos reclamaban el orden y otros lo repudiaban. Si todos fuesen como los primeros, la fuerza coercitiva no tendría razón de ser; pero, desgraciadamente, esta fuerza era requerida por necesidad. Por ello, resultaban imprescindibles para la sociedad los militares, ineludibles para el orden y respeto. Constituían un elemento de valor y de alta

12 Recordemos que, en la Argentina, entre la segunda mitad del siglo XIX y primeras décadas del XX, se produjo una fuerte oleada inmigratoria -proveniente especialmente de países europeos- que hizo aumentar en un tercio la población del país. Con los inmigrantes llegaron también nuevas ideas políticas y gremiales. 
consideración porque amaban la patria y su progreso (La Hoja Santiagueña, marzo de 1931); eran hombres correctos y caballeros. Los anarquistas, los "rusos" (judíos), los masones estaban en contra de esta fuerza. Los jefes de los militares era caballeros correctos, hombres de pundonor; con ellos la patria estaba bien custodiada (La Hoja Santiagueña, marzo de 1931).

Cuando abordaba temáticas relacionadas con las fechas patrias, generalmente exaltaba la participación de la Iglesia en la gesta de libertad o independencia. Tal el caso del 9 de julio de 1816, que en el acta de la Independencia, de los 21 firmantes, 16 eran sacerdotes y su redactor, fray Cayetano Rodríguez, era un fraile franciscano ( $\mathrm{La} \mathrm{Hoja}$ Santiagueña, agosto de 1933).

Los enemigos que atentaban contra las costumbres nacionales y cristianas atacaban por diferentes frentes. El comunismo en acción había iniciado su penetración por México y continuaba en la Argentina a través de los inmigrantes, ubicados en particular en las grandes ciudades como Buenos Aires y Rosario y en las provincias del litoral. Santiago del Estero no estaba exenta del peligro; los centros ferroviarios de La Banda, Santiago del Estero, Añatuya y Frías era bocas de entrada de estas ideas disolventes que alentaban la escuela atea, el amor libre y el divorcio, afirmaba.

Las sectas, como el Ejército de Salvación, la masonería y otras iglesias protestantes —evangelistas, adventistas - también atacaban a la nación; se prohibía a los católicos asistir a sus ceremonias o colaborar con ellas. Los protestantes constituían un peligro por ser divulgadores de propaganda imperialista norteamericana. El periódico calificaba de herejes a quienes practicaban alguna de las religiones protestantes.

\section{Las tradiciones}

Imbuido de ideas nacionalistas exaltaba la música nativa por su "sabor a patria”. La relación patria-tradición era indisoluble. Rescataba la figura del gaucho, como portador de esa tradición hispano-católica y a Andrés Chazarreta como exponente del canto nativo, además de colaborador permanente de la obra de la Iglesia santiagueña. 
Andrés Chazarreta, considerado "el patriarca del folclore" argentino, nació en Santiago del Estero hacia fines del siglo XIX. Luego de recibirse de maestro comenzó a ejercer en escuela católicas — de la Merced, San Francisco y del Círculo Católico de Obreros, del que fue uno de sus fundadores-. Además de desempeñarse como maestro en escuelas públicas, ocupó el cargo de inspector general de escuelas, puesto que le permitió recorrer gran parte de la provincia. Virtuoso de la música, aunque sin estudios previos, tocaba varios instrumentos y componía melodías populares, además de recopilar canciones y tonadas propias del acervo popular. Chazarreta salvó del olvido música y bailes del interior santiagueño, no sin tener que enfrentar oposición por parte de sectores ilustrados que menospreciaban la música autóctona. Fundador de la Compañía de Arte Nativo del Norte Argentino fue el primero en llevar la música folklórica a la capital de la República. ${ }^{13}$

La Hoja exaltaba la obra de Chazarreta, que había rescatado del olvido cantos y bailes nacionales, relegados en razón del avance de otros géneros musicales más propicios para el desarrollo de un "sentimentalismo vulgar y corrosivo" (La Hoja Santiagueña, 1 de diciembre de 1926). Seguía su derrotero por Tucumán y su gran triunfo en Buenos Aires, acompañado por su compañía que, con sus canciones y danzas, "destilaban amor a la tradición y a la patria" (La Hoja Santiagueña, agosto de 1937).

La publicación dominicana también destacaba el paisaje sencillo provinciano y la conservación de su flora, en particular del algarrobo, denominado el "árbol". ${ }^{14}$ Se rescataba al algarrobo como "símbolo de la supervivencia del alma nativa, dulce y cantora como sus danzas, sus vidalas y su armonioso parlar" (La Hoja Santiagueña, noviembre de 1934). Al final de la etapa, se observa el giro en la interpretación de las costumbres santiagueñas, en particular de las campesinas, más conocidas por los frailes gracias a misiones por el interior del monte santiagueño.

13 Sobre el tema ver Alen Lascano (1972) y Chazarreta (1965).

14 El taku, que brinda el acu, el patay y la aloja (acu, harina de algarroba; patay, torta de harina de algarroba y aloja, bebida fermentada). 


\section{Las festividades religiosas}

Eran motivo de atención de La Hoja las festividades religiosas propias de la comunidad dominicana, especialmente las de mayor devoción en la ciudad: la Sábana Santa y el Amo Jesús. La Sábana Santa, réplica pintada del Santo Sudario de Turín, llegó a Santiago del Estero hacia 1585, obsequio del rey Felipe II a los jesuitas. Luego de la expulsión de la Orden ignaciana, la reliquia quedó en custodia de la familia Díaz Gallo y, a partir de 1794, pasó a los dominicos. El lienzo muestra la imagen de Jesús con marcas físicas propias de la crucifixión. La pintura es doble - frontal y dorsal - respondiendo a la forma en que se envolvió el cuerpo de Cristo luego de su muerte. La imagen del Amo Jesús data de fines del siglo XVII. Se trata de imaginería alto peruana que representa a Jesucristo cargando la cruz en su hombro izquierdo, bajo cuyo peso inclina su figura doliente, y apoyando su mano derecha sobre una piedra, coronada su sien con espinas y expresión de dolor en su rostro, vestido con una túnica morada. La procesión del Amo Jesús junto con la imagen de la Dolorosa, convocaba a multitudes en el centro de la ciudad, el miércoles santo (Gramajo, 2003 pp. 122 a 145).

No podía faltar la fiesta de Santo Domingo de Guzmán y el encuentro de su imagen con la de San Francisco, el 3 de agosto. Encuentro similar se realizaba el 4 de octubre, para la festividad del Santo de Asís. El templo se engalanaba especialmente para la ocasión y los fuegos artificiales iluminaban la noche. Todo contribuía a dar realce a las celebraciones: arreglo especial de la iglesia, coro, orquesta, sermones a cargo de oradores de notoria fama, té y banquetes en el convento, a los que eran invitados las autoridades y "personas de distinción, afectas a la comunidad dominica" (La Hoja Santiagueña, agosto de 1928).

Para la Cuaresma hacía recomendaciones especiales sobre el ayuno y la abstinencia, no solo de carne sino también de espectáculos mundanos, el recogimiento piadoso y la penitencia (La Hoja Santiagueña, febrero de 1928). Para las celebraciones de Corpus Christi se engalanaba el templo para la función religiosa encabezada por sacerdotes dominicanos y franciscanos, que pronunciaban elocuentes discursos, coro a cargo de niñas del asilo de huérfanas, a cargo de las hermanas terciarias dominicas quienes, de este modo, buscaban integrarlas al 
tejido social. La procesión, con estaciones en distintos altares domésticos, coronaba la celebración con gran cantidad de público participante (La Hoja Santiagueña, 8 de julio de 1925).

En algunos casos las festividades coincidían con actos especiales en los que participaban integrantes de la jerarquía católica nacional, clero y fieles venidos de otras provincias en peregrinación. Tal el caso de la semana social organizada en memoria de San Francisco Solano y Santiago Apóstol, ${ }^{15}$ en 1928, en ocasión de la inauguración del seminario conciliar y la colocación de la piedra fundamental de la capilla del colegio de Belén. Asistieron a las celebraciones el arzobispo de Buenos Aires, junto a sacerdotes del clero regular de Buenos Aires, Tucumán, Catamarca y Córdoba quienes, unidos a los de Santiago del Estero, contribuyeron a dar brillo a la semana de reflexiones y festejos. Los conferencistas, monseñor Franceschi y el doctor Molas Terán ( $\mathrm{La}$ Hoja Santiagueña, agosto de 1928), entre otros, constituían un atractivo para público más intelectual, proveniente de sectores medios en ascenso. El catolicismo de masas se expresaba no solo en los templos sino también en las distintas actividades en las que participaban también autoridades civiles y militares.

El Teatro 25 de mayo, inaugurado en 1810 en ocasión del primer centenario de la revolución de mayo, era el escenario propicio para exteriorizar la adhesión política a las festividades, a la vez que estrechar vínculos con los sectores más encumbrados. Por lo general, La Hoja detallaba las celebraciones, con horarios para la asistencia de los fieles, misas, procesiones, sermones, entre otras. Estas festividades estaban pensadas, especialmente, para los fieles citadinos que concurrían al templo regularmente o en estas ocasiones especiales.

Diferente tratamiento se daba a las fiestas de la campaña. Entre las más importantes se destacaba la del Señor de los Milagros de Mailín. ${ }^{16} \mathrm{El}$

15 San Francisco Solano peregrinó por estas regiones a fines del siglo XVI; Santiago Apóstol era el patrono de la provincia.

16 El Cristo de Mailín es una pequeña cruz de madera que se venera en la pequeña localidad de Mailín, a $145 \mathrm{~km}$. de Santiago del Estero. La festividad se celebra el día de la Asención del Señor y congrega a multitudes católicas que se reúnen para adorar al "santo", Tenti, (2014) 
periódico ponía de relieve como hombres y mujeres, venidos de diferentes lugares, atravesando considerables distancias, por caminos intransitables, con falta de agua, de forraje para los animales y de lugares cómodos en donde pasar el día y las noches frías, llegaban a la pequeña población a realizar sus ofrendas al "santo" de Mailín.

Si bien no ignoraba las otras motivaciones que movilizaban a las multitudes católicas, tales como los juegos de azar y diversiones con bailes regionales, poesías y tradiciones - ya que el espacio campestre se transformaba en un espacio de socialización de los sectores populares- resaltaba la religiosidad popular en la procesión central. La Hoja destacaba también la presencia de familias distinguidas, que participaban de la celebración en espacios reducidos, con acceso directo a la iglesia parroquial (La Hoja Santiagueña, 1 de junio de 1926).

Los dominicos realizaban misiones por el interior de la provincia en ocasión de las fiestas patronales -especialmente durante el priorato de Saldaña Retamar- en antiguos pueblos y en nuevas poblaciones surgidas a la vera del ferrocarril. ${ }^{17}$ Las fiestas de Manogasta comenzaban a fines de noviembre y terminaban el 4 de diciembre. En la vieja capilla, con altar de material, se veneraba a Santa Bárbara. El último día llegaban los promesantes a caballo y en coches; gente de diferentes lugares hacían sus campamentos alrededor del templo. Luego de la misa y procesión, los cultos terminaban con casamientos y bautismos. A la tarde la concurrencia pasaba a los bailes populares, que se realizaban en ramadones o a la sombra de frondosos árboles y se prolongaban hasta entrada la noche. A juicio del periódico, este era el "lado flaco de la fiesta”, por los desbordes de la concurrencia. Pronto los efectos

17 En Silípica el 2 de febrero y en Manogasta el 4 de diciembre, se celebraban las fiestas religiosas en honor a Nuestra Sra. de Monserrat y a Santa Bárbara, respectivamente. En Sumamao, en honor a la Virgen de la Merced, el 24 de septiembre, en la parroquia de Fernández, en honor de Nuestra Sra. de la Merced y de la Inmaculada Concepción; en Tuama -entre el 6 y 8 de diciembre-, en honor a la Virgen 'india'. La Purísima de Tuama está vestida de celeste y blanco y, según la tradición, había sido nombrada Generala del Ejército por Manuel Belgrano (creador de la bandera nacional), en su paso por Santiago del Estero, rumbo al norte. Por ello, cientos de banderas argentinas la escoltaban en su procesión. 
de la bebida se hacían ver en múltiples desórdenes y el paisano perdía "el poco beneficio espiritual sí asistió a misa, y eso una vez al año", agregaba (La Hoja Santiagueña, febrero de 1934).

"Pasados los cultos en la sombra de algarrobos al lado del río viejo se realizaban los bailes, viéndose zapatear al compás de un gato punteado o de una chacarera, a una que otra vieja gaucha, pisoteando los estruendos", en los intervalos se dejaba oír la voz de Coria o de los ciegos, Pallares y Lastra, tipos populares en la región, acompañados de violín y guitarra. Cantaban sus versos, la mayoría de los cuales "no tenían pie ni cabeza”, afirmaba (La Hoja Santiagueña, febrero de 1934).

Diferentes eran las festividades en pueblos de reciente formación. En Los Juríes, ${ }^{18}$ en ocasión de celebrarse la fiesta al patrono San José, el periódico relataba la festividad, en una zona en donde los cultivos reemplazaban a los quebrachales. Concurrían a la celebración criolla y extranjera, a caballo o en auto: los apellidos se mezclaban ${ }^{19}$ y todos asistían "de punta en blanco". Destacaba el sermón del dominico, la ausencia de hombres "solo media docena" y a comulgar "las mujeres con los oídos tapados con algodón”, total 100 comuniones para esa muchedumbre, que acompañó a San José en la procesión" (La Hoja Santiagueña, abril de 1935). Indudablemente, la fiesta era un lugar de socialización y esparcimiento de las multitudes católicas; corrida de sortija, bailes, banquetes y juegos constituían los mayores atractivos.

En estación Lugones, con 500 habitantes, la celebración de una semana patriótica-religiosa en 1934, a juicio del periódico "ha de quedar marcada como la muerte de Ibarra o la caída de los Taboada". Con bastante exageración, equiparaba dos coyunturas políticas muy fuertes en la historia provincial con la misión a Lugones:

La actuación de fray Reginaldo Saldaña Retamar y del curita Manuelito Feijóo, produjo revuelo, no por los cabritos carneados sino por el resurgimiento del fervor religioso en el ambiente de

18 Pueblo surgido a la vera del ferrocarril.

19 Ferroni, Gironelli, Hosffmann, Versnaber, Aman, Rauch, Sobrero, Saieck, Salinas, Mattos, Zapata, Garófoli, Lucatelli, Alderete, Carrizo, Rovelli, Gómez. 
algarrobos, quimiles e itines. Para esas villas campestres el 25 de mayo, 9 de julio o la aparición de un cura son el único esparcimiento calificado (La Hoja Santiagueña, 1 de octubre de 1934).

Los habitantes de los alrededores llevaban a los niños a la confirmación o a los óleos. No faltaban parejas de hombres de "gruesa pelambre y mujeres de largas trenzas" quienes, luego de convivir muchos años, se casaban. Las actividades religiosas eran numerosas: cánticos infantiles, procesión del Señor de los Olvidos, San Cayetano y de la Virgen de la Merced. Coros, rezos, himnos a la noche bajo el cielo, a la mañana a la misa y a la tarde a la novena y al rezo del rosario.

Para La Hoja, — avanzada la década de los años treinta- en estas fiestas se materializaba el crisol de razas. La influencia de la inmigración se hacía sentir en los nuevos parajes atravesados por el ferrocarril y los inmigrantes se incorporaban a la vida parroquial. Afirmaba con énfasis La Hoja:

Las criollas de soñadores ojazos y los criollitos de vivaz mirar rivalizan con los arabesitos de pelo rubio e inteligentes: los Azar, los Abdala, Amado, Jorge, los italianitos Rosi, Rosetti y se codean con los Rojas, Leguizamón, Maldonado, Ledesma, Gómez, Villavicencio, etc. La niñez de Lugones ha demostrado estar orientada hacia el idealismo patrio-religioso (La Hoja Santiagueña, 1 de octubre de 1934).

\section{Cierre}

Al analizar La Hoja Santiagueña se observa que su discurso radical fue variando según el momento. Existe cierta relación entre la radicalización del discurso del periódico y su proceso de modernización. La publicación pretendía actuar como órgano de disciplinamiento y control de las costumbres de la sociedad católica santiagueña, para contrarrestar el accionar de los enemigos al acecho —en particular del socialismo, del comunismo y del modernismo-y mostrar actividades 
que reflejaban la articulación del catolicismo con la sociedad de masas (Lida, 2012). Si bien no encontraba el eco esperado en la sociedad provinciana tenía un núcleo propio que recepcionaba su prédica. Modernizó y diversificó sus estrategias para llegar a mayor cantidad de público, lo que le permitió aumentar las páginas y la frecuencia y editar mayor cantidad de ejemplares.

Hacia fines de los años cuarenta se observa cierta apertura a considerar otros aspectos hasta entonces no tenidos en cuenta y a alentar la participación de sectores populares en las celebraciones eclesiásticas, aunque distinguiéndolas de la de grupos conformados por familias tradicionales y nuevos sectores medios en ascenso, en particular los inmigrantes, coincidiendo esto con cierta renovación en su discurso. Cambió la visión contraria a la inmigración por la inclusiva del crisol de razas, conteniendo a los extranjeros entre los sectores progresistas, integrados a la sociedad.

Su postura nacionalista se manifiesta en la referencia al pasado hispano-católico, en oposición al avance de ideologías "disociadoras" y, a la vez, se observa un guiño hacia las costumbres propias de la campaña santiagueña, relacionadas con el folclore y la tradición, especialmente en las festividades religioso-populares, cuyas costumbres no juzgaba con tanta severidad como a las del modernismo citadino.

Continuidades y rupturas en las prácticas religiosas, más allá de lo pregonado por La Hoja, dan cuenta de la convivencia de una religiosidad marginal y otra más tutelada en la que se plasma, al decir de Hervieu-Léger (2004), una religión en movimiento, en la que, a pesar de los intentos de atomización individualista se producía cierta comunidad religiosa fundada sobre creencias compartidas y afinidades sociales y culturales.

\section{Referencias}

Alen, L. (1972). Andrés Chazarreta y el folklore. Buenos Aires: Centro Editor de América Latina.

Auza, N. (1992). Católicos y liberales en la generación del 80. Buenos Aires: Ed. Culturales Argentinas. 
Auza, N. (2000a). Un indicador de la cultura bonaerense. El periodismo de 1877 a 1914. En Investigaciones y ensayos. Buenos Aires: Academia Nacional de la Historia.

Auza, N. (2000b). Revistas culturales de orientación católica en el siglo XX en Argentina. Anuario de Historia de la Iglesia (9): 329-347. Pamplona: Universidad de Navarra.

Chazarreta, A. (1965). El eterno juglar. Buenos Aires: Ricordi. El país

Di Stefano, R. y Zanatta, L. (2000). Historia de la Iglesia argentina. Desde la Conquista hasta fines del siglo XX. Buenos Aires: Grijalbo.

Esquivel, J. (2000). De la crítica a la modernidad a la crítica al neoliberalismo. En X Jornadas sobre Alternativas Religiosas en América Latina. Buenos Aires.

González, R. (2001). Los dominicos en Argentina. San Miguel de Tucumán: Universidad del Norte Santo Tomás de Aquino.

Gramajo de Martínez Moreno, A. (2003). Los dominicos en Santiago del Estero. Santiago del Estero: Ed. V Centenario.

Gramajo de Martínez Moreno, A. (2005). La Hoja Santiagueña, periódico para las familias católicas de Santiago del Estero. En Segundas Jornadas de Historia de la Orden dominicana en la Argentina. Actas San Miguel de Tucumán: Universidad del Norte Santo Tomás de Aquino.

Guzmán, D. (2011). Historia de las revistas culturales de Santiago del Estero: el antipositivismo católico. En Tasso, A. (Ed.). Nuevos estudios de la historia de Santiago del Estero. Santiago del Estero: Inst. la Sagrada Familia.

Hervieu-Léger, D. (2004). El peregrino y el convertido. La religión en movimiento. México: Ed. del Helénico.

INDEC. (1917). Tercer censo nacional de 1914. Buenos Aires: Rosso y Cía.

INDEC. (1947). IV Censo General de la nación. Buenos Aires: Dirección General de Registro Estadístico.

La Hoja Santiagueña (1924-1943). Santiago del Estero. Biblioteca Inst. San Martín de Porres.

Lida, M. (2006) La prensa católica y sus lectores en la Argentina, 1880-1920. Tiempos de América (13): 59-71.

Lida, M. (2012). La rotativa de Dios. Prensa católica y sociedad en Buenos Aires. Buenos Aires: Biblos. 
Mallimaci, F. (1988). El catolicismo integral en la Argentina (1930-1946). Buenos Aires: Biblos Fund. Simón Rodríguez.

Pérez Agote, A. y Santiago, J. (Ed.). (2008). Religión y política en la sociedad actual. Madrid: Ed. Complutense.

Rointenburd, S. (2002). Católicos: entre la política y la fe (1862-1890). En Vidal, G. y Vagliente, P. (Comps.). Por la señal de la cruz. Estudios sobre Iglesia Católica y sociedad en Córdoba. XVII-XX. Córdoba: Ferreira.

Tenti, M. (2004). La reforma de la Constitución santiagueña de 1939 y la cuestión religiosa. Nuevas Propuestas, (36): 81-96.

Tenti, M. (2008b). Periodismo católico y política. El Momento de Santiago del Estero. En Folquer, C. y Amenta, S. (Eds.). Sociedad, Cristianismo y Politica. Tejiendo historias locales. San Miguel de Tucumán: Centro Promocional de Investigaciones en Historia y Antropología y Universidad del Norte Santo Tomás de Aquino.

Tenti, M. (2013). La formación de un Estado periférico. Organización del Estado santiagueño (1875-1916). Santiago del Estero: Universidad Católica de Santiago del Estero.

Tenti, M. (2014). Catolicismo de masas en Santiago del Estero. La festividad del Señor de los Milagros de Mailín a principios del siglo XX. En Aguirre, A., Abalo, E. (Coords.). Representaciones sobre historia y religiosidad. Deshaciendo fronteras. Rosario: Prohistoria.

Zanatta, L. (2002). Del Estado liberal a la nación católica. Iglesia y ejército en los orígenes del peronismo. 1930-1943. Bernal, Buenos Aires: Universidad Nacional de Quilmes. 



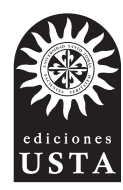

Esta obra se editó en Ediciones USTA,

Departamento Editorial de la Universidad Santo Tomás.

Se usó papel propalcote de 300 gramos para la carátula y papel bond beige de 75 gramos para páginas internas.

Tipografía de la familia Sabón. Impreso por Grupo Dao Digital, S.A.S. 2017. 


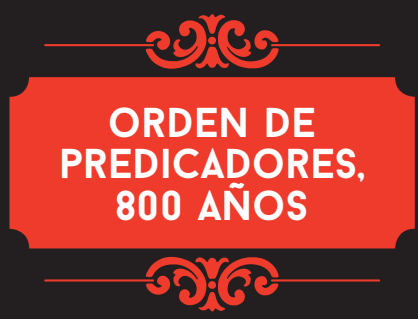

Desde antes de la confirmación pontificia de la Orden de Predicadores el 22 de diciembre de 1216, lo político ha estado presente en la vida y los quehaceres de los frailes dominicos. No obstante, esa presencia no se reduce a lo que en la llustración y en los siglos XIX y XX concibieron por política, es decir, la ciencia y el ejercicio concernientes al gobierno de las sociedades, sobre todo de los Estados nación, tampoco se agota en el concepto griego de polis o policía, sino que parte de dos conceptos de la tradición cristiana: el de persona, entendido como sustancia individual de naturaleza racional, y el de bien común o de todo aquello que es en beneficio de todas las personas.

En este libro, fruto de la contribución de una amplia red de historiadores, se estudia la participación de los dominicos en diversas disyuntivas en las que, en tanto homo politicus, los frailes han estado enfrentados al ineludible papel de tomar partido en los procesos políticos asumidos por los grupos sociales en los que han estado presentes a lo largo y ancho del mundo. 